\title{
The Impact Of The Question-Driven Technique On Developing Efl Jordanian Seventh Graders' Grammatical Competence
}

\author{
Dr. Ahmad Al-Zawahrah \\ EFL Supervisor, Ministry of Education, Ajloun, Jordan
}

Doi:10.19044/esj.2021.v17n15p124

Submitted: 19 April 2021

Accepted: 12 May 2021

Published: 31 May 2021
Copyright 2021 Author(s)

Under Creative Commons BY-NC-ND

4.0 OPEN ACCESS

Cite As:

Al-Zawahrah A. (2021). The Impact Of The Question-Driven Technique On Developing Efl Jordanian Seventh Graders' Grammatical Competence.

European Scientific Journal, ESJ, 17(15), 124. https://doi.org/10.19044/esj.2021.v17n15p124

\begin{abstract}
This research paper is aimed to examine the impact of the questiondriven technique on developing EFL Jordanian seventh graders' grammatical competence. To this end, the researcher has redesigned the targeted grammatical material and constructed a grammar test focusing mainly on those grammatical themes given in the seventh grade textbook. The researcher has selected two sections (A \& B) of the seventh grade; section A was assigned as a control group, the other one was assigned as an experimental group. The results of the study revealed that the students who have been taught inductively through the Questioning technique had gained better scores than those who have been taught deductively. It has also shown that the majority of the experimental group had more willingness and desire to participate in the class discussion. Also, it can be noticed that the use of the questioning technique is suitable for all types of learning styles and proficiency levels. Another important aspect to which the results of this study could be attributed is the adequate number of opportunities given for students to practice the targeted grammatical rules. In this regard, it sounds important to raise the strong effect of the scaffolding and modelling strategies in facilitating and easing the implementation of the questioning technique while teaching grammar.
\end{abstract}

Keywords: Question-Driven Technique, Seventh Graders, Inductive Methodology, Grammatical Competence 


\section{Introduction}

Learning a foreign language is exactly like constructing a building. As blocks and bricks are considered the cornerstones to construct a building, structures and rules are also regarded as the backbone for learning any foreign language. In this regard, it is vitally important for teachers of English as a foreign language (EFL) to be knowledgeable not only of the different structures and forms but rather of the modern methodologies to be capable of teaching any target language professionally. Before expecting a higher level of linguistic product from EFL students, it is very critical to paving the way by starting with accuracy-based instruction. Despite giving accuracy a priority in this stage, this does not contradict with the premise of language skills integration, especially using modern and effective instructional methodologies.

According to many researchers (Canale \& Swain, 1980; Omaggio, 2001), communicative competence consists of three pillars; grammatical competence, sociolinguistic competence, and strategic competence. The significance of grammatical competence resides in its invaluable role in enabling EFL learners to formulate meaningful and correct sentences and utterances. This means that the focus of this competency is not merely on accuracy but rather on fluency (Ellis, 2008; Ur, 2012). However, having a satisfying level of grammatical competence plays a pivotal role in EFL learner's learning cycle process since it helps them to overcome not only the verbal communication challenges but also those non-verbal communication problems. Thus, learning a foreign language requires both gaining a sufficient understanding of language grammar and using that language communicatively (Fitriati, Isfara, and Trisanti, 2017).

\section{Statement of the Problem}

In spite of this recognition and admission of the significance of the Grammatical competence in setting the scene for learning and acquiring foreign and second languages, there are still some setbacks and shortcomings that hinder the EFL learning process, especially the instructional methodology followed by many EFL teachers. In other words, like other macro language skills (listening, speaking, reading, and writing), teaching grammar as a microlanguage skill is oftentimes taught abstractly and intangibly.

In contrary to the deductive methodology which goes hand in hand with the top-down approach where EFL teachers begin their Grammar lessons with the rules as a first step leaving no room for students to think moving on to the second step by giving examples about the target rules and finally ending the lesson with some quick exercises, the inductive methodology harmonizes with the bottom-up approach where EFL teachers do not follow the same steps followed above but rather they try to provide students with as much exposure 
to the target language as possible (Mallia, 2014). In other words, what weakens the deductive methodology is the style practiced by EFL teachers in terms of time, focus, and presentation. That is to say, the teacher is still a sage on the stage i.e., the teacher occupies most of the class time giving very little time for students to use and practice the target language.

\section{Significance of the Study}

For the sake of bridging the existing gap between what is supposed to be practiced on the ground by EFL teachers and those flexible and effective teaching principles stipulated by several scholars such as shifting from sage on the stage to guide by the side for McWilliam (2009), from deductive -based instruction to inductive-based instruction, from 20/80 (teacher-centered) to 80/20 (student-centered) and from theory to practice, the researcher will address the grammatical competence that learners are supposed to master taking into consideration the aforementioned principles particularly by using one of the inductive methodology techniques (the question-driven). To be more accurate, the researcher is going to examine the impact of the questiondriven technique on improving the seventh graders' grammatical competence, particularly past simple and continuous, present simple and continuous, and finally comparative and superlative.

EFL teachers who follow the inductive methodology have special ways of dealing with the target grammar themes, for example, they may use games, songs, stories, questions, dialogues or conversations. In contrast to the deductive methodology which has been delineated by Crystal (2003) as ruleoriented, the different modes of the inductive methodology are implicit-based and bottom-up as they focus on meaning and context. According to Wilson and Smetana (2011), learners are supposed to be familiar with the scaffolding and modelling strategy in order to extract the rules on their own.

Besides, the encouragement to use the inductive methodology has been spotted in several studies by many researchers such as (Benitez-Correa, Gonzalez-Torres, Ochoa-Cueva, \& Vargas-Saritama 2019; Dang and Nguyen, 2012; Nalunga, 2017). For these researchers, the inductive approach has proved its effectiveness in varied EFL contexts especially for teaching grammar. For example, Benitez-Correa, et.al, (2019) have found out that the inductive approach does not only affect students' proficiency level but rather it does strengthen the relationship between students and their teachers through those flexible and appealing inductive approach techniques.

This subconscious exposure to the target language has been clarified by Krashen (1981) in his renowned theory "second language acquisition" in which EFL learners are expected to be exposed to multi meaningful contexts to practice the interaction and communication skills. Furthermore, Krashen and Terrell (1983), emphasized the necessity of the comprehensible input 
hypothesis for language acquisition occurrence. According to this hypothesis, the input should match the proficiency level of the target students, i.e., it should not be very difficult in order not to discourage students or very easy to kill the spirit of competitiveness. This hypothesis, indeed, supports the natural progress of language because it is learner-centered not like the Grammar translation which is teacher-centered.

\section{Operational Definitions}

Question-driven technique is one of the models of the inductive methodology that is based on providing students with sufficient opportunities to practice the target language meaningfully and authentically with the teacher's guidance and assistance. Unlike the deductive methodology which is teacher-centered, the inductive methodology, which is represented in this research study by the question-driven technique, is student-centered. According to Iannelli (2016), the questioning technique is used by EFL students to aid them in comprehension not only in one specific phase of learning but rather in all phases of learning. That is, it could be used in the prelearning stage by activating the learners' schemata, in the while and postlearning stages to facilitate understanding and to stretch out learning respectively. It does not stop at that edge but it could be used by the end of the lesson to check, evaluate and assess students' learning and this is what is known as Assessment of learning".

Inductive Methodology is an instructional methodology used by EFL teachers to develop students' proficiency level in the English language by:

1 - increasing the dose of exposure to the target language;

2- activating the role of students by increasing their interaction and participation in the classroom;

3- providing students with ample meaningful opportunities to practice the target language

4- changing the classroom atmosphere from the static model into a more flexible and appealing one.

To achieve these objectives, there are different techniques and forms through which EFL teachers can successfully implement the inductive methodology such as games, stories, questioning and dialogues.

Grammatical competence is the ability of the seventh graders to use the grammatical themes given in Grade seven communicatively and meaningfully. These themes are "present simple and continuous, past simple and continuous, and comparative and superlative". This competence has been measured in this study through a written achievement-test constructed by the researcher. In this study, the target Grammar competency means the set of rules that allow EFL learners to combine words in their language to come up with larger units of oral and written speech. Ur (1988) asserted that "there is 
no doubt that a knowledge - implicit or explicit - of grammatical rules is essential for mastery of a language: you cannot use words unless you know how they should be put together ” (p. 4).

\section{Literature Review}

Undoubtedly, the use of the questioning technique has been used in different fields of science for a long time. For example, the ancient Greek philosopher "Socrates" and Einstein are considered pioneers in this regard. They used to ask their students questions instead of giving direct information or responses (Filiz, 2009). It has been historically proved that the questioning strategies have a strong ability in provoking students' curiosity, problemsolving, critical-thinking skills, and recalling information. To do so, EFL teachers should change their role to be guides by the side to engage students and facilitate their learning (Dillon, 1990).

In one of her famous working hypotheses, Omaggio (2001) focused on the necessity of providing EFL students with ample opportunities (sufficient exposure) to practise the target language meaningfully and authentically. Accordingly, the use of the question-driven technique as one of the forms of the inductive methodology has been chosen for the sake of changing the learning and teaching atmosphere and shifting the roles of both teachers and students to fulfill the modern orientation of pedagogy represented by the principles that have been already mentioned. This means that asking students proper questions can foster interaction and understanding between the teacher and their students (Van Lier, 1988).

In his research paper entitled, "Teaching Grammar in Context: Why and How?", Mart (2013) explained the reason and the proper mechanism of introducing Grammar to EFL learners. For him, the best way to do so is by teaching grammar in context, especially by using dialogues. The use of dialogues as one of the indirect forms of teaching grammar is useful because it shows the learners how language is used in real-life situations (Thornbury, 1999). By having a look at those dialogues, one can easily notice that the major constituent of these dialogues is the use of questions. According to Mart, genuine conversations are considered an excellent means to facilitate EFL learners' apprehending the targeted grammatical themes. By the end of his study, he concluded saying that teaching grammar in context will help learners to acquire new structures and forms and that Learners will be ready to use grammatical conventions more effectively in communications if they are exposed to them in context.

Regarding the possibility of the questioning technique in developing higher thinking skills, Etemadzadeha, Seifi, and Far (2012) asserted that the questioning technique is very powerful in provoking students' interest and desire to think and write. They found out that using the questioning technique 
does not only motivate students to develop their critical thinking but rather it leads them to be more active in producing language, including speaking and mostly writing, since it is believed that good writing results from good thinking.

Moreover, Wilson and Smetana (2011) proposed a questioning technique entitled "Question as thinking" to be used within the classroom. It is a mix of both questioning and thinking aloud for the sake of gaining comprehension from the given text. They believe that such a technique guides students through their learning step by step enabling them to be more autonomous and confident. They concluded that having the ability to use the questioning technique as a thinking tool on their own, students are expected to have no problem in dealing with any text regardless of the difficulty level it may have due to the progress of their metacognitive faculty. For them, the use of such a technique cannot be successfully carried out in contexts that have passive learners.

According to a research study conducted by Khotimah (2017) in which she examined the effect of questioning techniques on students' ability in writing narrative texts, the researcher found out that there was a significant difference in the students' ability in writing narrative texts attributed to the use of the questioning technique. The results of the study have also shown that the students' English competence especially in writing was getting better by implementing the questioning technique recommending EFL teachers to activate the use of the questioning technique to enhance the students' ability in writing.

In another study conducted by Fitriati, Isfara, and Trisanti (2017) in which they examined the influence of the EFL teachers' questioning skills on enhancing EFL secondary school students' verbal responses, the study has shown that teachers' questioning skills are crucial to successfully make students more engaged in the classroom interaction, enhance students' verbal responses, and lead to the comprehension of the lesson suggesting that teachers should be more aware of their questioning skills to assist students to achieve better proficiency in the English language.

Alzu'bi (2014) conducted a comparative study to investigate the effectiveness of teaching English grammar by using deductive and inductive teaching models. The researcher designed two programs based on inductive and deductive methods. The results of his study revealed that there were significant statistical differences at $(\alpha \leq 0.09)$ among the grammar performance means of both groups at both levels in favour of the inductive method. On the other hand, in a comparative analysis of the inductive and the deductive methods in teaching English conducted by Farahani (2018) by which the major purpose was to compare the efficiency of these two approaches in teaching English grammar by inspecting students' performance 
implementing the test-teach-test design, the achieved scores in the tests indicated that both the inductive and the deductive methods were equal in terms of efficiency. These results came to support Muhammad \& Jaber's study (2008) who concluded that there was no significant difference between the deductive and inductive approaches and there was no significant effect for the interaction between the approach and class.

In the same regard, Lafta (2019) conducted a study to examine the effect of deductive and Inductive Approaches on Iraqi EFL college students learning of grammar. For this purpose, two groups of students were taught the order of adjectives through deductive and inductive approaches and then they were given an identical exam to measure their understanding after the lesson. The results of the study indicated that there was a slightly higher level of achievement as well as a higher level of satisfaction in favor of the group which was taught deductively.

\section{Methodology Data Collection Technique}

In order to examine the impact of the question-driven technique as one of the models of the inductive methodology on upgrading EFL Jordanian seventh graders' grammatical competence, the researcher has used a quasiexperimental design which requires an experimental group and a control group for comparison. To this end, the researcher has constructed a grammar test to be applied to both groups before and after the intervention (the treatment). The test has been validated before the execution process by a set of specialists and experts. The researcher has first redesigned the targeted grammatical material (see appendix 1) and then constructed a grammar test focusing mainly on those grammatical themes given in the seventh-grade textbook. The grammatical themes included present simple and continuous, past simple and continuous, comparative and superlative.

\section{Findings}

In light of the results of the study, particularly in Table 1 , one can notice that there is a significant increase in the scores of those students who were taught deductively; this appeared between the grammar pre-test and the post-test. An increase has also been noticed between the pre- and post-test scores of the group that was taught inductively as shown in Table 2 below. In other words, we can conclude that at the time the development level in the deductive methodology moved from fair to good, it was better and more noticed in the inductive methodology going from fair to very good. 
Table 1. Deductive methodology group

\begin{tabular}{|l|c|c|}
\hline \multicolumn{1}{|c|}{ Statistic } & Pre-test & Post-test \\
\hline Mean & 3.514 & 5.750 \\
\hline Standard Deviation & 0.661 & 0.941 \\
\hline \multicolumn{2}{|c|}{} \\
\end{tabular}

Table 2. Inductive methodology group

\begin{tabular}{|c|c|c|}
\hline Statistic & Pre-test & Post-test \\
\hline Mean & 3.667 & 6.501 \\
\hline Standard Deviation & 0.689 & 1.057 \\
\hline \multicolumn{2}{|c|}{} \\
\end{tabular}

The initial results have also revealed that there has been no significant difference between the pre-test scores of both the deductive and inductive groups before the intervention which means that both groups have had a similar level of grammar competence. After the intervention, a significant difference in the post-test has been observed (see Table 3). The results of this study are in harmony with Khotimah's research results in which she found that the questioning technique has a positive impact on EFL students writing competency. In congruence with this, Fitriati, Isfara and Trisanti (2017) found out that the questioning skills have played a crucial role in enhancing EFL students' verbal responses. Benitez-Correa, et.al (2019) found out that the inductive approach especially the questioning technique does not only improve students' proficiency level but rather cementing the relationship between students and their teacher. This also confirms what has been demonstrated by many educators who believe in using the questioning technique as an engine to drive the entire learning and teaching process.

Table 3.Results of the post-test in the deductive and inductive groups

\begin{tabular}{|c|c|c|}
\hline Statistic & Deductive & Inductive \\
\hline Mean & 5.750 & 6.501 \\
\hline Standard Deviation & 0.941 & 1.057 \\
\hline \multicolumn{2}{|c|}{$\mathrm{t}=2.1998$} \\
$\mathrm{p}=0.0349$
\end{tabular}

\section{Reflective Discussion of the Results}

In light of the results of the pre-and post-test, it has been deduced that the students who have been taught inductively have gained better scores than those who have been taught deductively. Also, it has been noticed that the majority of the experimental group students have more willingness and desire to participate in the class discussion. This could be attributed to the comfort and safety given to students by their teacher who does not focus on every single grammar mistake or error committed by students in the class. 
Another important aspect to which the results of this study could be attributed is the adequate number of opportunities given for students to practice the targeted grammatical rules. This was through those ready-made worksheets which were smartly and meaningfully designed for the sake of using the target language as much as possible and extracting the rules on their own. In this regard, it sounds important to raise the strong effect of the scaffolding and modelling strategies in facilitating and easing the implementation of the questioning technique while teaching grammar. This was cautiously addressed while preparing the worksheets. In other words, instead of focusing on one type of questions (wh-questions), it would be more beneficial to include the other type of questions (Yes, No / and Yes, No with options) to guarantee the participation of as many students as possible. (See appendix 1)

It was also noticed that high achieving students did not have any problem in dealing with wh-questions as a means to communicate with each other and to extract the rules whereas low achieving students were in need of Yes, No questions especially when they are accompanied with options as a means to increase their interaction and understanding. Unlike other strategies and techniques that may take a long time for students to be acquainted with, it has been observed that the students of the experimental group took a very short time in getting on with the questioning technique.

Luckily, in light of my random and systematic observations, it has been noticed that very few students (low achieving students) had some challenges in responding to wh-questions, therefore, a box of useful language for each grammar theme, including prompts, hints, and starters was prepared and distributed to students in need. Since the ultimate goal of using the questioning technique is to motivate students' fluency and linguistic competency, students' minor mistakes and errors have not been directly corrected. For example, I heard some students using some irregular verbs incorrectly especially in the past tense while talking about what they did in the morning before going to school, when they got to school, when they went back home, but I did not interrupt and correct them directly. Oftentimes, I gather as many mistakes and errors as possible in order to display them in the class to discuss them and to draw students' attention to those mistakes to avoid committing them in the future.

Based on the findings and the positive impacts of this study and other research studies, one can conclude that the questioning technique can be adapted to serve the EFL learners' needs not only in one particular language skill but rather in almost all language skills. Also, it can be noticed that the use of the questioning technique is suitable for all types of learning styles and proficiency levels. More importantly, the success of attaining such positive 
results relies on having qualified staff who are capable of using such techniques and strategies professionally.

\section{References:}

1. Alzu'bi, M.A. (2015). Effectiveness of inductive and deductive methods in teaching grammar. Australian International Academic Centre, 6 (2), 187-194.

2. Benitez-Correa, C., Gonzalez-Torres, P., Ochoa-Cueva, C., \& VargasSaritama, A. (2019). A Comparison between deductive and inductive approaches for teaching EFL grammar to high school students. International Journal of Instruction, 12(1), 225-236.

3. Canale, M. \& Swain, M. (1980). Theoretical Bases of Communicative Approaches to Second Language Teaching and Testing: Applied Linguistics (3rd ed.). Boston: Heinle.

4. Crystal, D. 2003. The Cambridge Encyclopedia of the English Language. (2nd ed.). Cambridge: Cambridge University Press.

5. Dang, T. \& Nguyen, H.(2012). Direct Versus Indirect Explicit Methods of Enhancing EFL Students' English Grammatical Competence: A concept Checking Based Consciousness-Raising Tasks Model. English Language Teaching, 6(1), 112121.

6. Dillon, J. T. (1990). The Practice of Questioning, London, Routledge.

7. Ellis, R. 2008. The study of Second Language Acquisition. (2nd ed.). Oxford: Oxford University Press.

8. Filiz, S. (2009). Question and answer method to ask questions and technical information on the effects of teacher education. Social Sciences Journal of Caucasus University, 2 (9), 1167-1175.

9. Fitriati, S. W., Isfara, G. A. V., \& Trisanti, N. (2017). Teachers' questioning strategies to elicit students' verbal responses in EFL classes at a secondary school. International Journal of Global Education, 1(8), 26-34.

10. Iannelli, R. (2016)."The effects on student understanding when questioning techniques are used during the reading of informational text". Theses and Dissertations . 574. https://rdw.rowan.edu/etd/574

11. Krashen, S., \& Terrell T. (1983). The Natural Approach: Language Acquisition in the Classroom. Oxford: Pergarmon.

12. Krashen, S. D. (1981). Second Language Acquisition and Second Language Learning. Oxford: Pergamon.

13. Lafta, N. (2019). The Effect of Deductive and Inductive Approaches on Iraqi EFL College Students Learning of Grammar. University of Thi-Qar Journal, 14 (3), 55-66.

14. Mallia, J. G. (2014). Inductive and Deductive Approaches to Teaching English Grammar. AWEJ Journal, 5 (2), 221 -235. 
15. Mohammed, A., \& Jaber, H.(2008). The Effects of Deductive and Inductive Approaches of Teaching on Jordanian University Students' Use of the Active and Passive Voice in English. College Student Journal, 42(2), 545-553.

16. Omaggio, A.H. (2001). Teaching Language in Context (3rd ed.). Boston: Heinle.

17. Thornbury, S. (1999). How to Teach Grammar. Essex: Pearson Education Limited.

18. Ur, P. (2012). A course of English language teaching. Cambridge: Cambridge University Press.

19. Van Lier, L. (1988). The Classroom and the Language Learner. London: Longman.

20. Wilson, N., \& Smetana, L. (2011). Questioning as thinking: A metacognitive framework to improve comprehension of expository text. Literacy UKLA, 45(2), 84-90.

\section{Appendix 1}

Re-designing the Grammatical Themes inductively in a Questiondriven form

Instead of introducing the grammar activities according to what is stated in the Teacher's Book, the Student's Book, and the Activity Book, the researcher has redesigned those grammar activities and themes based on the Question-Driven Technique.

(This is a sample of both the original and the re-designed material of the grammar activities before and after modification)

Source: https://moe.gov.jo/ar/node/79572

\section{Before modification}

The Present Simple (affirmative)

Complete this paragraph with the verbs in the correct form.

\begin{tabular}{|lllll|}
\hline Feel be & like & work & have \\
\hline
\end{tabular}

Salma (1) is a nurse. She (2)-----------at night.

Night, I (4)-----------time to talk to Salma: I (3) ------------ my job. At

people. And people (5)----------- they (6) -------------- not alone.

\section{After modification}

Who is Salma? / Is Salma a nurse or a teacher?

When does Salma work? / Does Salma work in the day or at night?

Does Salma like her job? / Why does Salma like her job?

Does Salma have time to talk to people? When does she have time to talk to people? 
How do patients in the hospital feel?/ Do patients in the hospital feel happy or sad?

Note: Please write your answers in full and complete forms

For further practice, students are invited to answer the following questions about themselves but after modelling this by their teacher.

\section{My Daily Routine}

When do you get up every day? / Do you get up early or late?

When do you pray Al-Fajr prayer? Do you pray on time or late?

Where do you pray ? Do you pray in the mosque or at home?

What do you do before going to school? Do you have your breakfast at home alone or with your family?

Do you practice some sport? Do you surf the net? Do you read the guidelines? Do you feel upset or relaxed in the morning?

How do you go to school? Do you go alone or with others?

How far is it from your home to school? Is it far or close?

How long do you stay at school? Do you feel bored or excited?

When do you go back home? Do you go back home late or early?

When do you have your lunch? Do you have lunch directly after getting home? When do you do your homework? Do you do your homework after or before lunch?

What do you do before going to bed? Do you play video games, go walking, watch a movie, recite some verses from the Holy Qura'n, etc.?

After Modification (present simple with adverbs of frequency)

\begin{tabular}{|llll}
\hline Always usually sometimes often never &
\end{tabular}

In pairs, read the following questions about Global Warming and try to answer them based on your knowledge and experience. Students are urged to take turns asking and answering the questions and then to write the answers on their notebooks:

Do you fight global warming?

Do you turn off the water tap while brushing your teeth?

How often do you turn off the water tap while brushing your tap?

Do you walk to school or go by bus?

How often do you go to school on foot / by bus?

Does your family recycle paper cups and supermarket bags?

How often does your family recycle paper cups and supermarket bags?

Do you turn off the lights when you leave a room?

How often do you turn off the lights when you leave a room?

Do you turn off the computer when you don't use it?

How often do you turn off the computer when you don't use it? 


\section{Before Modification (Present simple)}

Match the verbs with their opposite.
a. to slow
1. to freeze
b. to heat up
2. to accelerate
c. to warm
3. to make cold
d. to melt
4. to cool

6 Fill in the blanks with six verbs from exercise 5.

The sun (1) the air. Humid hot air rises and expands. Expansion (2) the air and makes clouds and rain. The sun also (3) up the

Earth. As the Earth heats up, the ice in the Poles (4) . Pollution (5) this process. We have to (6) it down.

\section{After Modification (present simple)}

What heats up the air? Does the sun heat or cool the air?

What does expansion do? Does expansion cool or melt the air?

What does the sun do to the Earth? Does the sun warm up or cool the Earth?

What happens to the ice in the Poles when the Earth heats up?

Does the ice in the Poles melt or freeze when the Earth heats up?

Does pollution accelerate or decrease ice melting in the poles?

What should we do to slow down pollution?

\section{Useful prompts and hints}

We can recycle: newspapers, white paper, mixed-colour paper, magazines, junk mail, plastic bags, milk bottles, juice bottles, water bottles

Go to school on foot, by bus / turn off the water tap when brushing teeth/ turn off the lights/ turn off the computer when we don't use it

We cannot recycle: yoghurt containers, rubber bands, plastic stickers, plastic food wraps, syrup bottles, nappies, bottle tops

\section{(past simple)}

Question-Based Games (Find someone who-------)

Note: Such an activity could be used at the beginning of the class as a kind of a warming-up activity to pave the way for students to be more active and to practice the targeted teaching point adequately.

\begin{tabular}{|l|l|l|}
\hline$\#$ & Items & Name \\
\hline 1 & ate Mansaf yesterday & \\
\hline 2 & drank orange juice last week & \\
\hline 3 & went to the child museum last summer holiday & \\
\hline 4 & watched a movie last night & \\
\hline 5 & wrote a story last year & \\
\hline 6 & read a book last month & \\
\hline 7 & travelled to another country & \\
\hline 8 & visited the Dead Sea & \\
\hline
\end{tabular}




\begin{tabular}{|l|l|l|}
\hline 9 & played video games yesterday & \\
\hline 10 & fasted a day last month & \\
\hline
\end{tabular}

Note: To help students carry out such games easily and successfully, the teacher must provide students with sufficient and clear instructions about the game. He is also required to model the game in front of them to show them exactly how to implement it.

\section{Before Modification}

6 Rewrite the following sentences using the correct form of the verbs in bold. 1- Archaeologists who explore Jordan discover that it is a rich historical location.

In the last century, archaeologists who explored Jordan discovered that ...

2. Many people live in this area.... during ancient times.

3. Citizens work hard on building their cities using materials which are available around them.

In the past, ...

4. The markets attract people from various locations.

Many years ago, ...

\section{After Modification}

Who explored Jordan?

What did they discover?

Did archaeologists discover that Jordan was a rich or poor location?

Did many people live in Jordan? When was this?

Who worked hard on building the Jordanian cities? What did citizens use to build their cities?

What attracted people from various locations?

Were people attracted by libraries or markets?

\section{Before modification}

Complete the passage with the correct form of these verbs.

Be live not change disappear be

The wonders of the ancient world were places where people (1) lived.

(2) Were there many wonderful locations in the past?

Yes, there (3) was a large number of historical places that were unique. Some of these wonders (4) did not change at all over the years, but some (5) disappeared after many years.

\section{After Modification}

Did people live in the wonders of the ancient world?

Were there many wonderful locations in the past?

Were historical places unique or normal?

Did these wonders change over the years? 
Did some of these wonders or all the wonders disappear over the years?

\section{Before modification}

\section{The Past Simple (irregular verbs)}

1- In pairs, find the Past Simple forms of these irregular verbs in the texts on pages 55 and 56.

\begin{tabular}{|llll|}
\hline sit take think & give \\
\hline
\end{tabular}

2-Now in pairs, complete this dialogue with the verbs from the list. Two words are used more than once.

\begin{tabular}{|llll|}
\hline was thought were became wrote & w \\
\hline
\end{tabular}

The character Sherlock Holmes (1) was a professional detective. He (2) thought fame (3) was not important. Watson (4) wrote his stories for people to know Holmes' role in them. Holmes' tools (5) were science, logic and observation of small details. His techniques, such as examining fingerprints, later (6) became a reality in police investigations. Next time you are in London, visit his famous apartment at 221b Baker Street. It (7)became a museum in 1951.

\section{After Modification}

Who was Sherlock Holmes?

Was Sherlock Holmes a professional detective?

Did Sherlock Holmes think that fame was important?

Why did Watson write his stories?

What were Holmes' tools?

Holmes used several tools in his career. Mention two of them.

One of Holmes' techniques became a reality in police investigations. What was that technique?

\section{Before modification}

Compare the two books in the photos. Use the adjectives in the list to write sentences

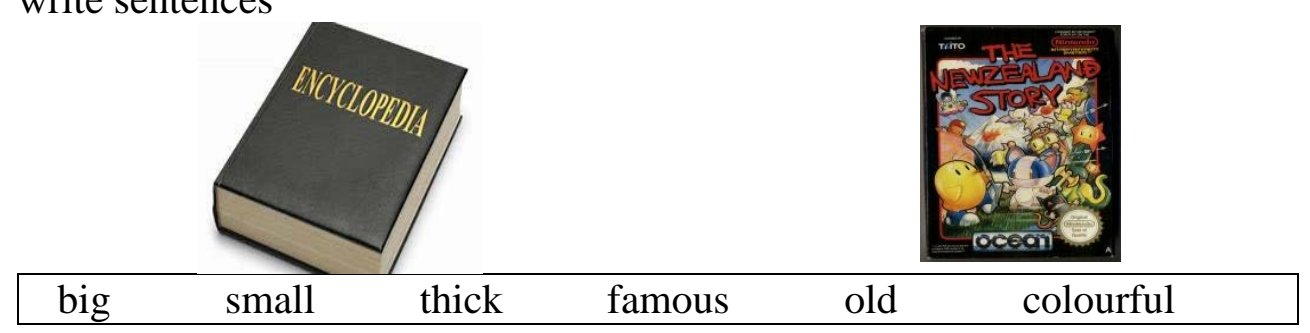

Instructions: Read the questions below, then in pairs answer them giving full answers.

For example: "The encyclopedia is bigger than the story." 
Which is bigger the encyclopedia or the story?

Which is smaller the encyclopedia or the story?

Which is thicker the encyclopedia or the story?

Which is more famous the encyclopedia or the story?

Which is older the encyclopedia or the story?

Which is more colourful the encyclopedia or the story?

After answering the questions above, the students are asked to take turns asking and answering the questions orally as a kind of extra practice.

\section{Before modification} brackets.

Complete this dialogue with the correct form of the adjectives in

Raed: I saw one of Poirot's stories on TV yesterday! Fatima: Poirot? I don't like him. I only love Miss Marple. Raed: Miss Marple! That boring old lady! Fatima: She's not boring. In any case, she's (1)---------- (boring) than Poirot. Raed: She's (2) ------------------- (intelligent) than Sherlock Holmes. Holmes and Poirot are (3)------------- (logical) and (4) ------------ (professional) than Miss Marple. Fatima: Maybe, but she’s (5)---------- (old) and (6)-------- (wise) than them. Raed: In any case, I like detective stories. They are (7)-----------(interesting) than romantic novels.

\section{After Modification}

Based on the text above, answer the questions below in full forms:

\section{For example: Miss Marple is less boring than Poirot.}

Who is more boring Miss Marple or Poirot?

Who is less boring Miss Marple or Poirot?

Who is more intelligent Miss Marple or Sherlock Holmes?

Who is less intelligent Miss Marple or Sherlock Holmes?

Are Poirot and Holmes less or more professional than Miss Marple?

Is Miss Marple less or more professional than Poirot and Holmes?

Who is older Miss Marple or Poirot?

Who is wiser Miss Marple or Holmes?

Which is more interesting a detective story or a romantic novel?

Are detective stories more or less interesting than romantic novels?

Note: To provide students with more practice and to enable them to get more familiar with comparative and superlative forms, it is recommended to begin or end the class with the following activity:

Find someone in the class who is

\begin{tabular}{|l|l|l|}
\hline$\#$ & Items & Names \\
\hline 1 & taller than you & \\
\hline 2 & more courageous than you & \\
\hline 3 & more patient than you & \\
\hline
\end{tabular}




\begin{tabular}{|l|l|l|}
\hline 4 & more intelligent than you & \\
\hline 5 & less intelligent than you & \\
\hline 6 & more logical than you & \\
\hline 7 & less logical than you & \\
\hline 8 & happier than you & \\
\hline
\end{tabular}

Note: When reporting the results to class, please follow the following sample as an example: Ahmad is taller than me this means that I am shorter than him.

Samir is more courageous than me this means that I am less courageous than him.

\section{Before modification}

Complete the text by the new detective Sameer. Use the comparative form of the adjectives from the list.

Courageous patient logical intelligent hard

Hello! I'm Sameer. I finally passed the test and became a real detective, but Joe didn't. It wasn't so easy; in fact, it was (1) than we expected. I was (2) than Joe and didn't give up thinking about the solutions of the different problems. The head detective said that I was (3) than Joe since all the solutions I suggested made perfect sense. Although Joe is (4) than I am, he couldn't solve all the problems. I think he was a bit scared of failing; I was (5) than him and didn't care about the test results.

\section{After modification}

Based on the text above, answer the following questions:

Was the test harder or easier than they expected?

Who was more patient Sameer or Joe?

Who was more logical Sameer or Joe? Support your answer with a piece of evidence from the text.

Who is more intelligent Sameer or Joe?

Who was more courageous Sameer or Joe? Support your answer with a piece of evidence from the text.

\section{Before Modification}

Complete this table with the superlative form of the adjectives.

\begin{tabular}{|c|c|c|}
\hline Adjective & Comparative & Superlative \\
\hline old & Older than & the oldest \\
\hline pleasant & more pleasant than & the most pleasant \\
\hline hot & Hotter than & ---------------------------- \\
\hline famous & more famous than & -------------------------- \\
\hline good & Better than & ---------------------------- \\
\hline
\end{tabular}




\section{After modification}

Who is the oldest in your family?

What is the hottest city in your country?

Who is the most famous person in your village?

Who is the best student in your class?

What is the worst game/ sport for you? 